University of Wollongong

Research Online

Faculty of Business - Papers (Archive)

Faculty of Business and Law

$1-1-2014$

Challenging behaviours, co-morbidities, service utilisation and service access among community-dwelling adults with severe traumatic brain injury: a multicentre study

\author{
Grahame K. Simpson \\ Liverpool Hospital, University of Sydney, Ingham Institute of Applied Medical Research \\ Mark Sabaz \\ Liverpool Hospital \\ Maysaa Daher \\ Ingham Institute of Applied Medical Research \\ Robert Gordon \\ University of Wollongong, robg@uow.edu.au \\ Barbara Strettles \\ Ingham Institute of Applied Medical Research
}

Follow this and additional works at: https://ro.uow.edu.au/buspapers

Part of the Business Commons

Research Online is the open access institutional repository for the University of Wollongong. For further information contact the UOW Library: research-pubs@uow.edu.au 


\title{
Challenging behaviours, co-morbidities, service utilisation and service access among community-dwelling adults with severe traumatic brain injury: a multicentre study
}

\author{
Abstract \\ Objective: To examine patterns, predictors and unmet needs of service utilisation and access to mental \\ health and/or drug and alcohol services among community-dwelling adults with severe traumatic brain \\ injury, and compare those who displayed challenging behaviours with those not displaying challenging \\ behaviour. Design: Retrospective multicentre study.
}

Subjects: All active clients $(n=507)$ of the New South Wales (NSW) Brain Injury Rehabilitation Program (BIRP) community rehabilitation teams.

Methods: Clinician-rated data were collected on client challenging behaviours, mental health and functional status, service utilisation and unmet needs. Between-groups analyses (challenging behaviour versus no challenging behaviours) were conducted to examine patterns of service utilisation and unmet needs. Predictors for service utilisation were tested by multiple linear regression.

Results: Challenging behaviours were associated with higher use of BIRP and non-BIRP services and greater levels of unmet needs. Challenging behaviour was an independent predictor of higher levels of service utilisation, in conjunction with pre- and post-injury mental health and drug and alcohol comorbidities and geographic location. Only $15.3 \%$ of the 111 clients with challenging behaviours and comorbid drug and alcohol problems accessed a drug and alcohol service, while another $32.4 \%$ had unmet needs for such services.

Conclusion: Challenging behaviours make an independent contribution to increased levels of service utilisation after severe traumatic brain injury.

\section{Keywords}

injury, brain, traumatic, challenging, severe, adults, multicentre, dwelling, study, community, among, access, utilisation, service, morbidities, co, behaviours

\section{Disciplines}

Business

\section{Publication Details}

Simpson, G. K., Sabaz, M., Daher, M., Gordon, R. \& Strettles, B. (2014). Challenging behaviours, comorbidities, service utilisation and service access among community-dwelling adults with severe traumatic brain injury: a multicentre study. Brain Impairment, 15 (1), 28-42. 


\title{
Challenging Behaviours, Co-morbidities, Service Utilisation and Service Access among Community-dwelling Adults with Severe Traumatic Brain Injury: A Multicentre Study
}

\author{
Grahame K. Simpson, ${ }^{1,2,3}$ Mark Sabaz, ${ }^{1}$ Maysaa Daher, ${ }^{3}$ Robert Gordon ${ }^{4}$ \\ and Barbara Strettles ${ }^{3,5}$ \\ ${ }^{1}$ Liverpool Brain Injury Rehabilitation Unit, Liverpool Hospital, Sydney, Australia \\ 2 John Walsh Centre for Rehabilitation Research, Sydney School of Medicine, University of Sydney, Australia \\ ${ }^{3}$ Brain Injury Rehabilitation Research Group, Ingham Institute of Applied Medical Research, Sydney, \\ Australia \\ ${ }^{4}$ Australian Health Services Research Institute, University of Wollongong, Australia \\ 5 Agency of Clinical Innovation, Sydney, Australia
}

\begin{abstract}
Objective: To examine patterns, predictors and unmet needs of service utilisation and access to mental health and/or drug and alcohol services among communitydwelling adults with severe traumatic brain injury, and compare those who displayed challenging behaviours with those not displaying challenging behaviour. Design: Retrospective multicentre study.

Subjects: All active clients $(n=507)$ of the New South Wales (NSW) Brain Injury Rehabilitation Program (BIRP) community rehabilitation teams.

Methods: Clinician-rated data were collected on client challenging behaviours, mental health and functional status, service utilisation and unmet needs. Betweengroups analyses (challenging behaviour versus no challenging behaviours) were conducted to examine patterns of service utilisation and unmet needs. Predictors for service utilisation were tested by multiple linear regression.

Results: Challenging behaviours were associated with higher use of BIRP and non-BIRP services and greater levels of unmet needs. Challenging behaviour was an independent predictor of higher levels of service utilisation, in conjunction with pre- and post-injury mental health and drug and alcohol co-morbidities and geographic location. Only $15.3 \%$ of the 111 clients with challenging behaviours and co-morbid drug and alcohol problems accessed a drug and alcohol service, while another $32.4 \%$ had unmet needs for such services.

Conclusion: Challenging behaviours make an independent contribution to increased levels of service utilisation after severe traumatic brain injury.
\end{abstract}

Keywords: challenging behaviours, traumatic brain injury, service utilisation, needs, mental health, drug and alcohol abuse

\section{Introduction}

Challenging behaviours are widespread after severe traumatic brain injury (TBI), with signifi- cant rates of aggression (verbal, physical), inappropriate sexual behaviour, perseveration, wandering/absconding, inappropriate social behaviour

Address for correspondence: Grahame Simpson, PhD, Liverpool Brain Injury Rehabilitation Unit, Liverpool Hospital, Sydney, NSW, Australia.E-mail: grahame.simpson@sswahs.nsw.gov.au 
and adynamia reported (Belanger et al., 2008; Colantonio, Howse, \& Patel, 2010; James \& Young, 2013; Kelly, Brown, Todd, \& Kremer, 2008; Rao et al., 2009; Sabaz et al., 2014; Simpson, Sabaz, \& Daher, 2013; Wood \& Liossi, 2006). A large number of negative impacts have been associated with such behaviours, including reduced independence, poor vocational status and lowered participation, while service providers and family caregivers have reported increased levels of stress and disruption (Feeney, Ylvisaker, Rosen, \& Greene, 2001; Grafman et al., 1996; Sabaz et al., 2014; Todd, Loewy, Kelly, \& Simpson, 2004; Wood \& McMillan, 2001). Despite the large body of research documenting challenging behaviours after TBI, there has been limited investigation into the implications that challenging behaviours have for service utilisation.

Service utilisation is an important focus of health services research. The increasing pressure on resources within health systems globally highlights the importance of understanding patterns of service use to inform policy, planning and funding processes. Furthermore, in terms of clinical management, the availability versus the lack of availability of services can have a significant impact on a person's quality of life after TBI (High et al., 1995; Hodgkinson, Veerabangsa, Drane, \& McCluskey, 2000; Marwitz, Cifu, Englander, \& High, 2001). Therefore, understanding patterns of service use can be critical to the process of developing and refining service structures to enhance individual function, participation and wellbeing over time (Sloan, Winkler, \& Callaway, 2004).

The few previous studies investigating service utilisation after TBI have found that the patterns of use vary significantly by injury severity and disability (Heinemann, Sokal, Garvin, \& Bode, 2002; High et al., 1995; Hodgkinson et al., 2000; Willemse-van Son, Ribbers, Stam, \& van den Bos, 2009) but have not focused on challenging behaviours per se. Therefore little is known about the pattern of service utilisation that might be associated with such behaviours. These include questions about the types of staff, the range of services provided and the number of agencies involved. Moreover, multivariate testing is needed to investigate whether challenging behaviours make an independent contribution to increased service utilisation after controlling for the existing variables reported in the literature.

The pattern and predictors of existing service utilisation form only part of the picture, however. Unmet needs reported by people with TBI also suggest gaps in service provision, with up to 35$40 \%$ of people with TBI reporting at least one such need in the first year post-injury alone (Corrigan,
Whiteneck, \& Mellick, 2004; Pickelsimer et al., 2007). Heinemann and colleagues (2002) developed an extensive list of 27 areas of needs specific to persons with TBI. Clients then identified their needs from this list, and also nominated which needs had been met by services received. The correlation between these needs and frequency of service use was low $(r=-.27)$, suggesting substantial levels of unmet needs.

There are still questions to be answered in relation to such needs. The three cited studies relied on client report. However, community-based rehabilitation staff can provide a complementary perspective about unmet service need. Rehabilitation professionals are privy to important information about available service systems as well as the blockages or bottlenecks that limit service access of which clients may not be aware. Furthermore, impairments in awareness may mean that clients with TBI underestimate their service needs. Finally, although many of the needs identified by clients in the earlier studies (e.g., improving mood, controlling temper, managing stress; Heinemann et al., 2002) may have been underpinned by challenging behaviour, the aggregated impact of such behaviours on unmet needs was not explicitly addressed.

An additional complication in the management of people with severe TBI is the presence of comorbid mental health or drug and alcohol problems (e.g., Corrigan et al., 2004; Koponen et al., 2002). A significant association has been found between such mental health and/or substance misuse comorbidities and challenging behaviours (Baguley, Cooper, \& Felmingham, 2006; Rao et al., 2009; Sabaz et al., 2014; Simpson et al., 2013). Clinical experience suggests that staff in brain-injury services (both rehabilitation and long-term community support) often face barriers in seeking access for their clients to needed mental health or drug and alcohol services (Sabaz, 2010), but the extent to which this is exacerbated by the presence of challenging behaviours has yet to be investigated systematically.

In examining the link between service utilisation, unmet needs, challenging behaviours and comorbidities, the organisational context will significantly shape the findings. Although many reports into the management of challenging behaviours derive from specialist neurobehavioural units (Alderman, 2007; Eames \& Wood, 1985; James \& Young, 2013), aged services (Colantonio et al., 2010; Winkler, Sloan, \& Callaway, 2010) or other residential settings (Manchester, Hodgkinson, \& Casey, 1997), most people with TBI, including those with challenging behaviours, reside and are managed in the community (Kelly \& Parry, 2008; 
Sabaz et al., 2014; Todd et al., 2004). The current study examined service utilisation within the context of the multidisciplinary community rehabilitation teams of the New South Wales Brain Injury Rehabilitation Program. The aims were to examine the patterns, predictors and unmet needs relating to service utilisation, as well as access to mental health and/or drug and alcohol services, among community-dwelling adults with severe TBI who displayed challenging behaviours and compare to those without challenging behaviour.

\section{Methods}

\section{Setting and Sample}

The New South Wales Brain Injury Rehabilitation Program (BIRP) comprises 11 adult and 3 paediatric services which provide a state-wide network of inpatient, transitional living and communitybased rehabilitation services for people with severe TBI. Established in 1991, the BIRP is part of the New South Wales state health department and constitutes the primary provider of specialist brain injury rehabilitation services across the state. Under Australia's universal healthcare system, anyone who sustains a severe TBI within New South Wales aged between 0 and 65 can access BIRP services. The Brain Injury Rehabilitation Directorate coordinates the BIRP and collects state-wide data about BIRP participants

The 11 adult services provide community rehabilitation, with smaller numbers of the services also having inpatient rehabilitation units and/or transitional living units. Referral criteria are standard across the network (i.e., meet age and injury criteria, live within the geographic boundary of the treating service) with no exclusionary criteria in terms of behaviour. The community rehabilitation teams are multidisciplinary, integrating case managers, allied health staff (physiotherapists, occupational therapists, speech therapists), psychologists (clinical and/or neuropsychology), social workers and rehabilitation physicians. Each team has a slightly different mix of these staffing types. The teams provide needs-based neurorehabilitation and community support to clients meeting the state-wide referral criteria. Approximately one quarter of the clients are less than 1 year post-injury, with half of the clients being more than 2 years post-injury (Sabaz et al., 2014). Clients receive a mix of rehabilitation and case-management services provided directly by the community rehabilitation teams, coupled with other needed support and treatment services accessed from government, non-government and private agencies across disability, family support, mental health, and drug and alcohol service sectors.
All clients of the 11 BIRP adult community rehabilitation teams who met the following inclusion criteria were included in the study: (1) between the ages of 18 and 65 years; (2) sustained a severe TBI (length of post-traumatic amnesia at 1 day or more, and/or Glasgow Coma Scale score of less than or equal to 8 (Teasdale, 1995); and (3) an active BIRP client. 'Active' was defined as having received at least three occasions of service from the treating BIRP community rehabilitation team in the 6 months leading up to the study.

\section{Measures}

Standardised measures. Three standardised measures were employed. These measures were all designed for the brain impairment population and have good reliability and validity. The Overt Behaviour Scale (OBS; Kelly, Todd, Simpson, Kremer, \& Martin, 2006) was the primary outcome measure. The OBS consists of nine subscales which measure the presence of challenging behaviour following acquired brain injury (ABI) over the previous 3 months. The nine subscales each have between 1 and 6 levels of behaviour (with higher levels indicating increasing severity) totalling 34 levels across the nine domains. A rating of zero on a level indicates absence, while a rating of one indicates presence of challenging behaviour. A total Severity score (range 0 to 34 ) is calculated by summing across the levels. Finally, a total Clinical Weighted Severity score (range 0-84) can be produced using the same 34 levels. While the Severity score gives each observed behaviour the same value, the Clinical Weighted score is calculated based on clinical opinion of the severity of each behaviour, with some behaviours weighted as more severe than others and given a higher score. The nine subscales are the Verbal aggression scale (4 levels), Physical aggression against objects (4 levels), Physical aggression against self (4 levels), Physical aggression against others (4 levels), Inappropriate sexual behaviour (6 levels), Perseveration/Repetition (3 levels), Wandering/Absconding (3 levels), Inappropriate social behaviour (5 levels) and Adynamia/ Lack of initiation (1 level). Additional five-point Likert scales are used to assess the frequency $(1=$ less than once per month to $5=$ multiple times daily $)$ and impact $(1=$ no impact to $5=$ extreme) of any identified challenging behaviour.

In an earlier study, Sabaz and colleagues (2014) devised a set of criteria using OBS data to generate a classification of challenging versus nonchallenging behaviours. The criteria comprised a composite of the severity data (clients meeting specified severity levels were automatically 
classified as challenging); frequency data (clients with lower severity levels of behaviour but occurring at frequency levels of multiple times daily were also classified as challenging); and impact data (clients who did not meet the severity or frequency criteria, but whose behaviour was rated as having a severe or extremely severe impact). More information about the process for generating the cut-off scores can be found in Sabaz et al. (2014).

The Disability Rating Scale (DRS; Rappaport, Hall, Hopkins, Belleza, \& Cope, 1982) was used to collect information on the level of functional ability. It comprises eight items, and produces a total score ranging from 0 to 29 (higher scores indicate higher disability). The scores can be used to classify clients into seven bands ranging from no disability to extremely severe disability. The Health of the Nation Outcome Scale-Acquired Brain Injury (HONOS-ABI; Coetzer \& Du Toit, 2001; Fleminger et al., 2005) was used to measure current neuropsychiatric sequelae. The 12 items each measure a separate domain of functioning, rated on a five-point Likert scale ( $0-4$; no problem, minor, mild, moderate, severe) with higher scores indicating greater severity (range 0 48). Four items within the HONOS-ABI specifically address mental health problems (self-directed injury; hallucinations/delusions/confabulation; depressive symptoms; other mental and behavioural problems) and one item addresses substance abuse (problem drinking or drug use).

Service utilisation and service access variables. A data protocol was devised to collect information on current service utilisation and access. Three items were devised by the project team, all experienced rehabilitation professionals, to measure current service utilisation. Item one listed all 11 types of BIRP staff working on the community rehabilitation teams. Item two listed the 11 categories of services that the BIRP staff provided. The third item listed 15 categories of non-BIRP services accessed from the government, non-government and private sectors, as well as an addition informal category of support provided by family/ friends. To measure unmet need, the fourth item provided the same categories as item 3, but asked staff to identify those services that were required but not received by the client. For each item, clinician raters were asked to tick as many categories as applied. Two of the categories in items three and four comprised mental health/psychotherapy services and drug and alcohol services, respectively. Current utilisation referred to the same 6month period as defined the 'Active' status of the clients.
In addition to the four items addressing service utilisation and unmet needs, two purpose-designed dichotomous items recorded the presence of preinjury alcohol and pre-injury mental health problems (yes versus no). A pre-injury drug and alcohol problem was defined as evidence of significant disruption to the person's life as a consequence of the abuse (e.g., incurring legal charges, loss of job, relationship breakdown). A pre-injury mental health problem was defined as any lifetime history of diagnosis of mental illness, admission to a psychiatric service, treatment by a psychiatrist, or being on medication to treat a mental health condition.

\section{Procedures}

Ethics approval was obtained from the relevant New South Wales Health Human Research Ethics Committees prior to conducting the study. Permission was sought to waive consent for the use of client personal information in the study. Approval was provided on the grounds that: (1) the study involved clinicians rating clients based on their own knowledge of the client (supplemented by reference to the medical files), with no client or family member contacted to collect data; (2) if consent was required, there was a risk that more of the most challenging clients would withhold consent, thereby creating a study bias; and (3) all data would be de-identified and aggregated to ensure the privacy of all participants.

Clinicians at each of the 11 BIRP services were asked to complete the measures and data protocol for the clients allocated to them. Clients were allocated to the clinician who was most familiar with them. To maximise reliability, research staff visited each of the 11 centres to provide training and support to the clinicians during the data collection process. In addition to completing the measures and protocol, clinicians were asked to indicate how accurate they considered their ratings for each client on a four-point scale (very accurate, mostly accurate, somewhat accurate, not at all accurate). Clinicians entered their data directly into a laptop Microsoft Access Program. Using the Brain Injury Rehabilitation Directorate client unique identifier, the demographic and injury information (sex, country of birth, main language spoken, indigenous status, geographic location, age at injury, time post-injury, length of post-traumatic amnesia and injury circumstance) were then retrieved from the Brain Injury Rehabilitation Directorate database. Missing data across these fields were noted. Further detail about the procedures can be found in a previous report (Sabaz et al., 2014). 


\section{Statistical Analyses}

Data were transferred onto PASW-18 (SPSS Inc., Chicago, Illinois, USA) for analysis. Descriptive statistics were generated for all study variables (demographic/injury variables, standardised measures, service utilisation items). For the initial univariate analyses, Mann-Whitney $U$ tests and simple binary logistic regressions were employed to test differences in the numbers of services used (challenging versus non-challenging behaviours) and unmet needs.

A total service utilisation aggregate variable (total service use) was obtained by summing the number of BIRP and non-BIRP services received by each client. Spearman's rank correlation coefficients were then employed to test the association among the measures (OBS, HONOS-ABI, DRS) and the aggregate score (total service use). Spearman's rank correlation coefficients were also conducted between the service utilisation aggregate (total service use) and sex, country of birth, geographic location, preferred language and indigenous status. The strength of the coefficients was interpreted by reference to Cohen (1992). Variables significantly associated with total service use were grouped into three blocks (demographic, pre-injury, current status) and entered into the regression model. A combination procedure of sequential and stepwise regression was employed to produce the most parsimonious model for predicting the total service utilisation aggregate. Finally, descriptive statistics were employed to examine the relationship between challenging behaviours, comorbidities, access to mental health and/or drug and alcohol services, and unmet needs.

\section{Results}

\section{Sample}

Data collection was conducted between November 2007 and August 2008, with 659 clients of the BIRP community rehabilitation teams rated. A total of 152 clients were excluded from the current analysis for either not meeting the injury severity criterion ( $n=36$, mild/moderate injuries; $n=79$, no data available) or due to having a clinician accuracy rating score of 'not at all accurate' $(n=35$; $n=2$, no data available). The sample demographic and injury profile of the final study sample $(n=$ 507) are displayed in Table 1.

A total of $54.4 \%(276 / 507)$ of clients were classified as challenging overall. Breaking this down into individual behavioural domains, the most common types of behavioural disturbance were socially inappropriate behaviour $(33.3 \%$, $169 / 507)$, verbal aggression $(27.2 \%, 138 / 507)$ and adynamia/lack of initiation $(23.1 \%, 117 / 507)$. After combining the four types of aggressive behaviour (verbal aggression, physical aggression against objects, physical aggression against self and physical aggression against others), any type of challenging aggressive behaviour is displayed among $31.9 \%(162 / 507)$ of the clients. Of those clients displaying challenging behaviours $(n=$ 276), 34.8\% (96/276) displayed only one type of behaviour, with the remaining $65.2 \%$ (180/276) displaying two or more different types.

\section{BIRP Service Delivery}

Staff providing services. First, the number of staff from the BIRP community teams providing services to the clients was examined. The mean number of staff involved with each client was $3.45 \pm 2.01(N=506$, range $1-9)$. There was no significant difference in the number of BIRP staff managing clients with and without challenging behaviour $(3.51 \pm 1.20$ versus $3.38 \pm 2.02$; Mann-Whitney $U=30357.5, p>.05$ ). Uniformly high percentages of clients were seen by some categories of staff (e.g., rehabilitation physicians and case managers) regardless of their challenging status. However, there were significant differences among other BIRP professionals (see Table 2). Clients with challenging behaviour were significantly more likely to be seen by social workers and clinical psychologists, but less likely to be seen by physiotherapists.

Categories of services provided by the BIRP. Next, the categories of services provided by the BIRP community teams to clients were examined. The mean number of services provided to clients was $2.89 \pm 1.81(N=507$, range $1-9)$. Clients with challenging behaviours received significantly more categories of services overall from the BIRP teams compared to clients without challenging behaviour $(3.20 \pm 1.96$ versus $2.52 \pm 1.55$; MannWhitney $U=25686.0, p<.001)$. In terms of specific service categories, clients with challenging behaviours were 5.6 times more likely to have been provided with behavioural therapy and 3.5 times more likely to have received behavioural support and crisis intervention services compared to clients without challenging behaviours (see Table 2).

\section{Non-BIRP Service Delivery}

The proportion of clients receiving additional services outside of the BIRP network was also documented (see Table 3). The mean number of additional types of services (not counting informal support received from family or friends) received by clients was $2.17 \pm 1.31(N=507$, 


\section{TABLE 1}

Demographic and Injury Characteristics ( $N=507)$

\begin{tabular}{|c|c|c|c|}
\hline Variables & $\begin{array}{l}\text { Sample } \\
(N=507)\end{array}$ & $\begin{array}{l}\text { Challenging } \\
\text { behaviour }(n=276)\end{array}$ & $\begin{array}{l}\text { No challenging } \\
\text { behaviour }(n=231)\end{array}$ \\
\hline \multicolumn{4}{|l|}{ Sex, $n(\%)$} \\
\hline Male & $390(76.9)$ & $222(80.4)$ & $168(72.7)$ \\
\hline Female & $117(23.1)$ & $54(19.6)$ & $63(27.3)$ \\
\hline \multicolumn{4}{|l|}{ Country of birth, $n(\%)(n=504)$} \\
\hline Australia & $390(77.4)$ & $220(79.7)$ & $170(74.6)$ \\
\hline Out of Australia & $114(22.6)$ & $56(20.3)$ & $58(25.4)$ \\
\hline \multicolumn{4}{|l|}{ Geographic location, $n(\%)(n=503)$} \\
\hline Urban & $332(66.0)$ & $170(62.0)$ & $162(70.7)$ \\
\hline Regional/remote & $171(34.0)$ & $104(38.0)$ & $67(29.3)$ \\
\hline \multicolumn{4}{|l|}{ Preferred language, $n(\%)(n=500)$} \\
\hline English & $451(90.2)$ & $248(91.5)$ & $203(88.6)$ \\
\hline Other & $49(9.8)$ & $23(8.5)$ & $26(11.4)$ \\
\hline \multicolumn{4}{|l|}{ Indigenous status, $n(\%)(n=472)$} \\
\hline Indigenous heritage & $17(3.6)$ & $14(5.3)$ & $3(1.4)$ \\
\hline Non-indigenous heritage & $455(96.4)$ & $248(94.7)$ & $207(98.6)$ \\
\hline \multicolumn{4}{|l|}{ Time post-injury, $n(\%)(n=498)$} \\
\hline Less than 1 year & $123(24.7)$ & $47(17.4)$ & $76(33.3)$ \\
\hline $1-2$ years & $111(22.3)$ & $60(22.2)$ & $51(22.4)$ \\
\hline $2-5$ years & $124(24.9)$ & $69(25.6)$ & $55(24.1)$ \\
\hline More than 5 years & $140(28.1)$ & $94(34.8)$ & $46(20.2)$ \\
\hline \multicolumn{4}{|l|}{ PTA duration, $n(\%)(n=479)$} \\
\hline 2-6 days & $62(12.9)$ & $26(10.2)$ & $36(16.1)$ \\
\hline 1-4 weeks & 159 (33.2) & 71 (27.7) & $88(39.5)$ \\
\hline $1-6$ months & $221(46.1)$ & $130(50.8)$ & $91(40.8)$ \\
\hline$>6$ months & 37 (7.7) & $29(11.3)$ & $8(3.6)$ \\
\hline \multicolumn{4}{|l|}{ Age at injury, years $(n=499)$} \\
\hline Mean (SD) & $32.7(14.2)$ & $31.8(13.4)$ & $33.8(15.0)$ \\
\hline \multicolumn{4}{|l|}{ Injury circumstances, $n(\%)$} \\
\hline MVA/MBA-related injuries & $319(62.9)$ & $178(64.5)$ & $141(61.0)$ \\
\hline Assaults & $63(12.4)$ & $37(13.4)$ & $26(11.3)$ \\
\hline Falls & $79(15.6)$ & $41(14.9)$ & $38(16.5)$ \\
\hline Sports/leisure injuries & $21(4.1)$ & $9(3.3)$ & $12(5.2)$ \\
\hline Other TBI & $25(4.9)$ & $11(4.0)$ & $14(6.1)$ \\
\hline Pre-injury drug/alcohol abuse, $n(\%)$ & $132(26.0)$ & 99 (35.9) & $33(14.3)$ \\
\hline Pre-injury mental health problem, $n(\%)$ & $71(14.0)$ & $49(17.8)$ & $22(9.5)$ \\
\hline \multicolumn{4}{|l|}{ OBS total clinical weighted score } \\
\hline Mean (SD) & $4.1(5.9)$ & $7.03(6.7)$ & $0.7(1.2)$ \\
\hline \multicolumn{4}{|l|}{ HONOS-ABI total $(n=506)$} \\
\hline Mean (SD) & $10.9(6.6)$ & $14.1(6.2)$ & $7.0(4.7)$ \\
\hline \multicolumn{4}{|l|}{ DRS total $(n=505)$} \\
\hline Mean (SD) & $3.7(3.5)$ & $4.5(3.3)$ & $2.6(3.4)$ \\
\hline \multicolumn{4}{|l|}{ DRS categories, $n(\%)$} \\
\hline No disability & $60(11.9)$ & $16(5.8)$ & $44(19.0)$ \\
\hline Mild disability & $88(17.4)$ & 27 (9.9) & $61(26.4)$ \\
\hline Partial disability & $149(29.5)$ & $74(27.0)$ & $75(32.5)$ \\
\hline Moderate disability & $148(29.3)$ & 108 (39.4) & 40 (17.3) \\
\hline
\end{tabular}




\section{TABLE 1}

Continued

\begin{tabular}{lcll}
\hline Variables & $\begin{array}{l}\text { Sample } \\
(N=507)\end{array}$ & $\begin{array}{l}\text { Challenging } \\
\text { behaviour }(n=276)\end{array}$ & $\begin{array}{l}\text { No challenging } \\
\text { behaviour }(n=231)\end{array}$ \\
\hline Moderate to severe disability & $44(8.7)$ & $39(14.2)$ & $5(2.2)$ \\
Severe disability & $6(1.2)$ & $6(2.2)$ & $0(0.0)$ \\
Extremely severe disability & $10(2.0)$ & $4(1.5)$ & $6(2.6)$ \\
\hline
\end{tabular}

$S D$, standard deviation; TBI, traumatic brain injury; OBS, Overt Behaviour Scale; HONOS-ABI, Health of the Nation Outcome Study-Acquired Brain Injury; DRS, Disability Rating Scale; MVA, motor vehicle accident; MBA, motor bike accident; PTA, post-traumatic amnesia.

\section{TABLE 2}

Proportion of Clients Receiving Various Staff Services and BIRP Services ( $N=507$ )

\begin{tabular}{|c|c|c|c|c|c|c|}
\hline & \multirow[b]{2}{*}{$\begin{array}{l}\text { Sample } \\
(n=507) \\
n(\%)\end{array}$} & \multirow[b]{2}{*}{$\begin{array}{l}\text { Challenging } \\
\text { behaviour } \\
(n=276) \\
n(\%)\end{array}$} & \multirow[b]{2}{*}{$\begin{array}{l}\text { No challenging } \\
\text { behaviour } \\
(n=231) \\
n(\%)\end{array}$} & \multirow[b]{2}{*}{ OR } & \multicolumn{2}{|c|}{$95 \% \mathrm{Cl}$} \\
\hline & & & & & Lower & Upper \\
\hline \multicolumn{7}{|l|}{ BIRP Staff } \\
\hline Social work & $145(28.6)$ & $97(35.1)$ & $48(20.8)$ & $2.066^{a}$ & 1.381 & 3.090 \\
\hline Clinical psychology & $155(30.6)$ & $95(34.4)$ & $60(26.0)$ & $1.496^{\mathrm{b}}$ & 1.018 & 2.198 \\
\hline Neuropsychology & $154(30.4)$ & $79(28.6)$ & $75(32.5)$ & - & - & - \\
\hline Occupational therapy & $234(46.2)$ & $123(44.6)$ & $111(48.1)$ & - & - & - \\
\hline Physiotherapy & $146(28.8)$ & $66(23.9)$ & $80(34.6)$ & $.593^{b}$ & 0.403 & 0.874 \\
\hline Diversional therapy & $45(8.9)$ & $28(10.1)$ & $17(7.4)$ & - & - & - \\
\hline Living skills educator & $21(4.1)$ & $14(5.1)$ & $7(3.0)$ & - & - & - \\
\hline Psychiatry & 24 (4.7) & $17(6.2)$ & $7(3.0)$ & - & - & - \\
\hline Rehabilitation physician & $344(67.9)$ & $186(67.4)$ & $158(68.4)$ & - & - & - \\
\hline Speech pathology & $119(23.5)$ & $64(23.2)$ & $55(23.8)$ & - & - & - \\
\hline Case manager & $358(70.6)$ & 195 (70.7) & $163(70.6)$ & - & - & - \\
\hline \multicolumn{7}{|l|}{ BIRP Services } \\
\hline Assessment & $269(53.1)$ & $148(53.6)$ & $121(52.4)$ & - & - & - \\
\hline Psychotherapy/counselling & 105 (20.7) & $69(25.0)$ & $36(15.6)$ & $1.806^{\mathrm{b}}$ & 1.154 & 2.826 \\
\hline Psychoeducation & $70(13.8)$ & 47 (17.0) & $23(10.0)$ & $1.856^{\mathrm{b}}$ & 1.089 & 3.163 \\
\hline Crisis intervention & $104(20.5)$ & $80(29.0)$ & $24(10.4)$ & $3.520^{\mathrm{a}}$ & 2.143 & 5.782 \\
\hline Case management & $388(76.5)$ & 209 (75.7) & 179 (77.5) & - & - & - \\
\hline Behaviour therapy & $29(5.7)$ & $25(9.1)$ & $4(1.7)$ & $5.562^{b}$ & 1.938 & 16.489 \\
\hline Allied health & $133(26.2)$ & $64(23.2)$ & $69(29.9)$ & - & - & - \\
\hline Behavioural support & 57 (11.2) & $45(16.3)$ & $12(5.2)$ & $3.555^{a}$ & 1.832 & 6.900 \\
\hline Respite & $22(4.3)$ & $17(6.2)$ & $5(2.2)$ & $2.967^{b}$ & 1.077 & 8.170 \\
\hline Cognitive training & $78(15.4)$ & $46(16.7)$ & 32 (13.9) & - & - & - \\
\hline Carer/family education & 208 (41.0) & 131 (47.5) & 77 (33.3) & $1.807^{a}$ & 1.259 & 2.594 \\
\hline
\end{tabular}

BIRP, Brain Injury Rehabilitation Program.

Behaviour Therapy refers to behaviour programs delivered directly to the client. Behavioural Support refers to provision of education, training and support to staff and family members supporting persons with challenging behaviours. $a_{p}<.001,{ }^{b} p<.05$. 


\section{TABLE 3}

Proportion of Clients Receiving Various Non-BIRP Services and with Unmet Needs for these Services $(N=507)$

\begin{tabular}{|c|c|c|c|c|c|c|}
\hline & \multirow[b]{2}{*}{$\begin{array}{l}\text { Sample } \\
(n=507) \\
n(\%)\end{array}$} & \multirow[b]{2}{*}{$\begin{array}{l}\text { Challenging } \\
\text { behaviour } \\
(n=276) \\
n(\%)\end{array}$} & \multirow{2}{*}{$\begin{array}{l}\text { No challenging } \\
\text { behaviour } \\
(n=231) \\
n(\%)\end{array}$} & \multirow[b]{2}{*}{ OR } & \multicolumn{2}{|c|}{$95 \% \mathrm{Cl}$} \\
\hline & & & & & Lower & Upper \\
\hline \multicolumn{7}{|l|}{ Non-BIRP Services } \\
\hline GP/specialist & $427(84.2)$ & $238(86.2)$ & $189(81.8)$ & - & - & - \\
\hline Community health service & $41(8.1)$ & $23(8.3)$ & $18(7.8)$ & - & - & - \\
\hline Mental health service & $57(11.2)$ & 47 (17.0) & $10(4.3)$ & $4.536^{a}$ & 2.236 & 9.199 \\
\hline Family psychoeducation & $10(2.0)$ & $5(1.8)$ & $5(2.2)$ & - & - & - \\
\hline Drug and alcohol service & $25(4.9)$ & $17(6.2)$ & $8(3.5)$ & - & - & - \\
\hline Behavioural management & $9(1.8)$ & $8(2.9)$ & $1(0.4)$ & - & - & - \\
\hline $\begin{array}{l}\text { Community agency/home } \\
\text { support }\end{array}$ & $84(16.6)$ & 55 (19.9) & $29(12.6)$ & $1.733^{b}$ & 1.063 & 2.826 \\
\hline Disability services & $51(10.1)$ & $31(11.2)$ & $20(8.7)$ & - & - & - \\
\hline Education assistance & $24(4.7)$ & $8(2.9)$ & $16(6.9)$ & $0.401^{b}$ & 0.168 & 0.955 \\
\hline Private care agency & $51(10.1)$ & $33(12.0)$ & $18(7.8)$ & - & - & - \\
\hline Vocational assistance & 100 (19.7) & $40(14.5)$ & $60(26.0)$ & $0.483^{a}$ & 0.309 & 0.754 \\
\hline Legal services & $106(20.9)$ & $77(27.9)$ & $29(12.6)$ & $2.695^{a}$ & 1.685 & 4.311 \\
\hline Counselling & $60(11.8)$ & $28(10.1)$ & 32 (13.9) & - & - & - \\
\hline Living skills training & $16(3.2)$ & $13(4.7)$ & $3(1.3)$ & $3.757^{b}$ & 1.057 & 13.348 \\
\hline Private physiotherapy & $41(8.1)$ & $19(6.9)$ & $22(9.5)$ & - & - & - \\
\hline Family/friend support & $317(62.5)$ & $186(67.4)$ & $131(56.7)$ & $1.578^{b}$ & 1.098 & 2.266 \\
\hline \multicolumn{7}{|l|}{ Unmet needs } \\
\hline GP/specialist & $69(13.6)$ & $54(19.6)$ & $15(6.5)$ & $3.503^{a}$ & 1.919 & 6.395 \\
\hline Community health service & $28(5.5)$ & $24(8.7)$ & $4(1.7)$ & $5.405^{b}$ & 1.847 & 15.814 \\
\hline Mental health service & 49 (9.7) & 46 (16.7) & $3(1.3)$ & $15.200^{a}$ & 4.660 & 49.574 \\
\hline Family psychoeducation & $51(10.1)$ & $37(13.4)$ & $14(6.1)$ & $2.400^{\mathrm{b}}$ & 1.263 & 4.559 \\
\hline Drug and alcohol service & $42(8.3)$ & $38(13.8)$ & $4(1.7)$ & $9.061^{a}$ & 3.183 & 25.795 \\
\hline Behavioural management & 57 (11.2) & $56(20.3)$ & $1(0.4)$ & $58.545^{a}$ & 8.035 & 426.584 \\
\hline $\begin{array}{l}\text { Community agency/home } \\
\text { support }\end{array}$ & 75 (14.8) & $57(20.7)$ & $18(7.8)$ & $3.080^{a}$ & 1.755 & 5.405 \\
\hline Disability services & $79(15.6)$ & $61(22.1)$ & $18(7.8)$ & $3.357^{a}$ & 1.920 & 5.871 \\
\hline Education assistance & $27(5.3)$ & $19(6.9)$ & $8(3.5)$ & - & - & - \\
\hline Private care agency & $28(5.5)$ & $20(7.2)$ & $8(3.5)$ & - & - & - \\
\hline Vocational assistance & $115(22.7)$ & 77 (27.9) & $38(16.5)$ & $1.965^{\mathrm{b}}$ & 1.271 & 3.040 \\
\hline Legal services & $24(4.7)$ & $21(7.6)$ & $3(1.3)$ & $6.259^{b}$ & 1.843 & 21.260 \\
\hline Counselling & $89(17.6)$ & $64(23.2)$ & $25(10.8)$ & $2.488^{a}$ & 1.508 & 4.103 \\
\hline Living skills training & $58(11.4)$ & $50(18.1)$ & $8(3.5)$ & $6.167^{a}$ & 2.859 & 13.305 \\
\hline Private physiotherapy & $20(3.9)$ & 13 (4.7) & $7(3.0)$ & - & - & - \\
\hline Family/friend support & 75 (14.8) & 57 (20.7) & $18(7.8)$ & $3.080^{a}$ & 1.755 & 5.405 \\
\hline
\end{tabular}

BIRP, Brain Injury Rehabilitation Program.

${ }^{a} p<.001,{ }^{b} p<.05$.

range 0-7). Clients with challenging behaviour received significantly more types of non-BIRP services than people without challenging behaviours $(2.33 \pm 1.35$ versus $1.99 \pm 1.25$; Mann-Whitney $U=27458.5, p<.05)$. The specific service types are displayed in Table 3. Clients with challenging behaviour were 4.5 times more likely to have received mental health services, but less likely to have received educational or vocational assistance compared to clients without challenging be- 


\section{TABLE 4}

Spearman Correlation Coefficients of Study Variables with Total Services Used ( $N=507)$

\begin{tabular}{lr}
\hline Variables & \multicolumn{1}{l}{$r$} \\
\hline Sex & .046 \\
Country of birth & $.124^{\mathrm{a}}$ \\
Geographic location & $.252^{\mathrm{a}}$ \\
Preferred language & $-.115^{\mathrm{b}}$ \\
Indigenous status & $-.100^{\mathrm{b}}$ \\
Age at injury & -.033 \\
Time post-injury & -.017 \\
PTA duration & .085 \\
Injury circumstance & -.036 \\
Pre-injury drug and alcohol abuse & $.200^{\mathrm{a}}$ \\
Pre-injury mental health problem & $.184^{\mathrm{a}}$ \\
OBS total clinical weighted score & $.264^{\mathrm{a}}$ \\
HONOS-ABI total score & $.308^{\mathrm{a}}$ \\
DRS total score & $.134^{\mathrm{a}}$ \\
\hline
\end{tabular}

PTA, post-traumatic amnesia; OBS, Overt Behaviour Scale; HONOS-ABI, Health of the Nation Outcome Scale-Acquired Brain Injury; DRS, Disability Rating Scale. ${ }^{a} p<.01,{ }^{b} p<.05$.

haviours. A number of clients also received informal (unpaid) support from family/ friends. Clients experiencing challenging behaviour were 1.6 times more likely to receive this type of support.

\section{Correlates of Service Utilisation}

The total number of services used (BIRP and nonBIRP services barring family/friends) were aggregated to create the outcome variable (total services used). The average number of aggregated BIRP and non-BIRP services used across the sample was $5.07 \pm 2.46(n=507$, range $1-16)$. Correlational analysis was then conducted to investigate the association between total services used and the 14 study variables (as depicted in Table 4). Higher service use was correlated significantly with variables spanning demographic, pre-injury and clinical domains (see Table 4). However, the strength of coefficients were generally small $(r=.10$ to .30$)$ with the HONOS-ABI and the OBS having the strongest correlations. All significant coefficients were below the .9 threshold for multicollinearity.

A model to predict total service use was then tested by multiple regression analysis. Independent variables with significant correlations to total service use were grouped into three blocks, comprising four demographic variables (geographic location, country of birth, preferred language, indigenous status); two pre-injury variables (history of drug and alcohol abuse, history of mental health problems), and three clinical variables (total scores on the OBS [clinical weighted score], HONOSABI, DRS). The blocks were entered using a combination of sequential and stepwise regression. The result of the regression analysis was significant $\left(F_{(5,454)}=27.71, p<.001\right.$, adjusted $\left.R^{2}=.184\right)$ accounting for $18.4 \%$ of the variance. Geographic location (resident of rural/remote as opposed to urban locations), a pre-injury history of mental health problems or drug and alcohol abuse (purpose designed variables), as well as higher levels of current challenging behaviour (OBS) or current co-morbid mental health problems (HONOS-ABI) were all significant individual predictors of total service use $(p<.05)$. Level of functional ability (DRS) was not a significant predictor of total service use $(p>.05)$. Table 5 shows the regression coefficients and standard errors for the predictor variables.

\section{Unmet Needs}

As a measure of unmet need, clinicians also identified additional services that were required but had not been accessed or received by the client (see Table 3). Overall, the mean number of unmet services for clients was $1.60 \pm 2.18(N=507$, range $0-12)$. Over half of the clients were identified as having at least one unmet need $(58.2 \%, 295 / 507)$. Clients with challenging behaviour had a significantly higher amount of unmet needs than those without challenging behaviour $(2.31 \pm 2.53$ versus $0.75 \pm 1.21$; Mann-Whitney $U=18289.5, \mathrm{p}<$ $.001)$. Although high proportions of clients saw a general practitioner, people with challenging behaviours were 3.5 times more likely to have unmet needs in accessing this service. People with challenging behaviours were significantly more likely to have unmet needs in all service areas, with the exception of education assistance, private care agencies and physiotherapy. The two largest odds ratios, both with wide $95 \%$ confidence intervals, were a function of the small cell sizes for clients without challenging behaviours (see Table 3 ). For 8 of the 15 service types, the unmet need (clients for whom the service was required but not accessed) was greater than the number of clients accessing such services.

\section{Service Access for Clients with Co-morbid Mental Health or Drug and Alcohol Problems}

Aspects of access to mental health and drug and alcohol services were also investigated. First, mental health and drug and alcohol services were accessed by $32.4 \%(23 / 71)$ of clients with a pre-injury 


\section{TABLE 5}

Multiple Regression Analysis for Predictors of Total Service Use ( $N=507)$

\begin{tabular}{lllllll}
\hline & & & & & $95 \% \mathrm{Cl}$ for $B$ \\
\cline { 3 - 7 } Variable & $B$ at step & $S E_{B}$ at step & $\beta$ at step & $R^{2}$ change & Lower & Upper \\
\hline 1. Geographic location & 1.227 & 0.238 & $0.235^{\mathrm{a}}$ & 0.055 & 0.761 & 1.694 \\
2. Pre-injury drug and alcohol abuse & 1.044 & 0.252 & $0.187^{\mathrm{a}}$ & 0.034 & 0.550 & 1.539 \\
3. Pre-injury mental health problem & 1.044 & 0.320 & $0.148^{\mathrm{a}}$ & 0.021 & 0.414 & 1.673 \\
4. OBS total clinical weighted score & 0.110 & 0.018 & $0.267^{\mathrm{a}}$ & 0.067 & 0.074 & 0.145 \\
5. HONOS-ABI & 0.056 & 0.019 & $0.147^{\mathrm{b}}$ & 0.015 & 0.018 & 0.093 \\
Constant & 2.555 & 0.347 & & & 1.872 & 3.238 \\
\hline
\end{tabular}

$B$, unstandardised regression coefficients; $S E_{B}$, standard error of the coefficient; $\beta$, standardised coefficients; $\mathrm{Cl}$, confidence intervals.

OBS, Overt Behaviour Scale; HONOS-ABI, Health of the Nation Outcome Scale-Acquired Brain Injury. ${ }^{a} p<.001,{ }^{b} p<.05$.

mental health problem and $14.4 \%(19 / 132)$ of clients with pre-injury drug and alcohol problems, respectively. Next, the pattern of mental health service use for people with current mental health problems was examined. The four HONOS-ABI items that were used to address current mental health status (psychotic features, self-directed injury, depressive symptoms, other mental/behavioural problems) were cross-tabulated with access to mental health services. The results suggested a differential pattern of access to mental health services based on the type of problem (see Figure 1). For clients rated in the severe category, $75 \%$ and $50 \%$ with psychotic features or self-directed injury, respectively, accessed mental health services. However, less than $40 \%$ of those classified with severe depressive symptoms or other mental health problems (most commonly anxiety-related) accessed such services.
To examine the relationship between challenging behaviours, post-injury co-morbidities and service use, two new binary variables (presence versus absence of a current mental health or current drug and alcohol problem) were created using ratings from the HONOS-ABI. Clients with ratings no higher than 'mild' across any of the four mental health subscales were recoded as 'no to minimal problem' $(75.3 \%, 382 / 507)$. Clients with a rating of moderate or severe on any one of the four subscales were recoded as having a significant current mental health problem $(24.7 \%$, 125/507). Similarly, people were classed as having a significant current drug and alcohol problem (moderate or severe, $30.0 \%, 152 / 507$ ) versus no to minimal problem $(70.0 \%, 355 / 507)$ using the relevant HONOS-ABI item.

Two-by-two contingency tables were then constructed. The tables represented four possible

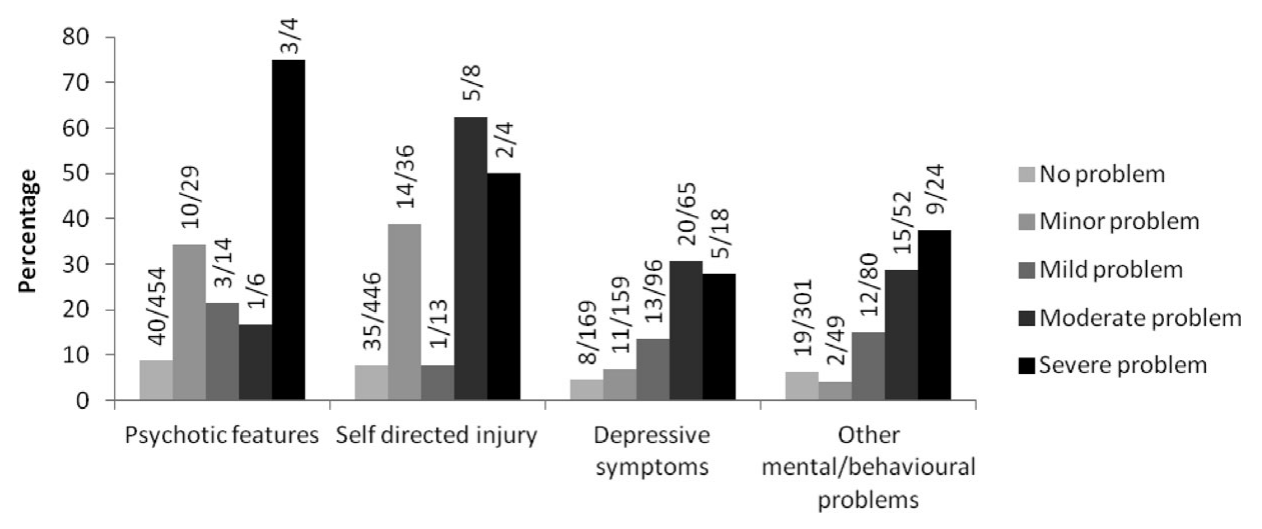

\section{FIGURE 1}

Specialist mental health service access across different types of mental health problems $(N=507)$. 


\section{Mental Health Co-morbiditv}

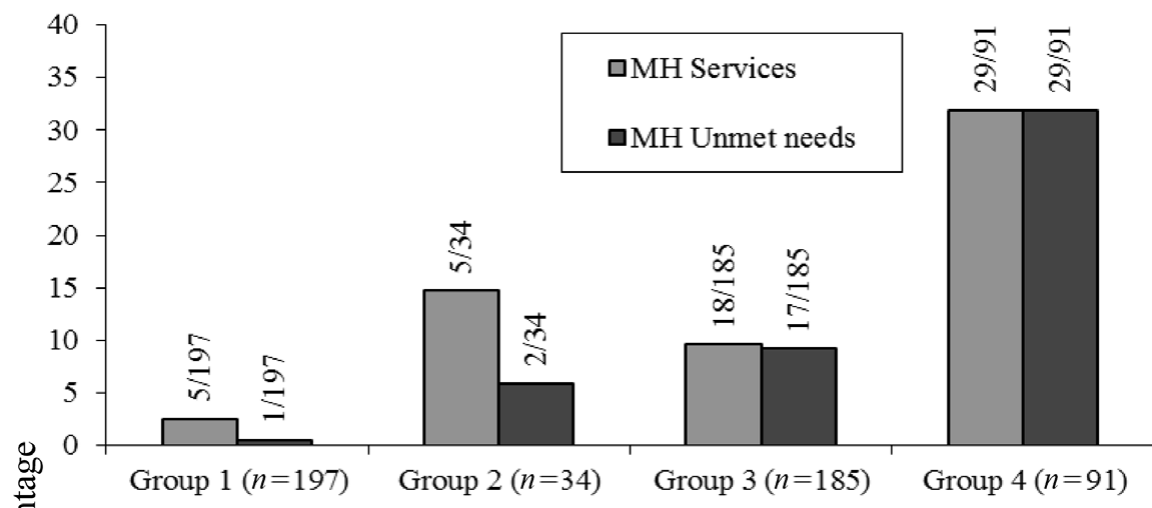

\section{Drug and Alcohol Co-morbiditv}

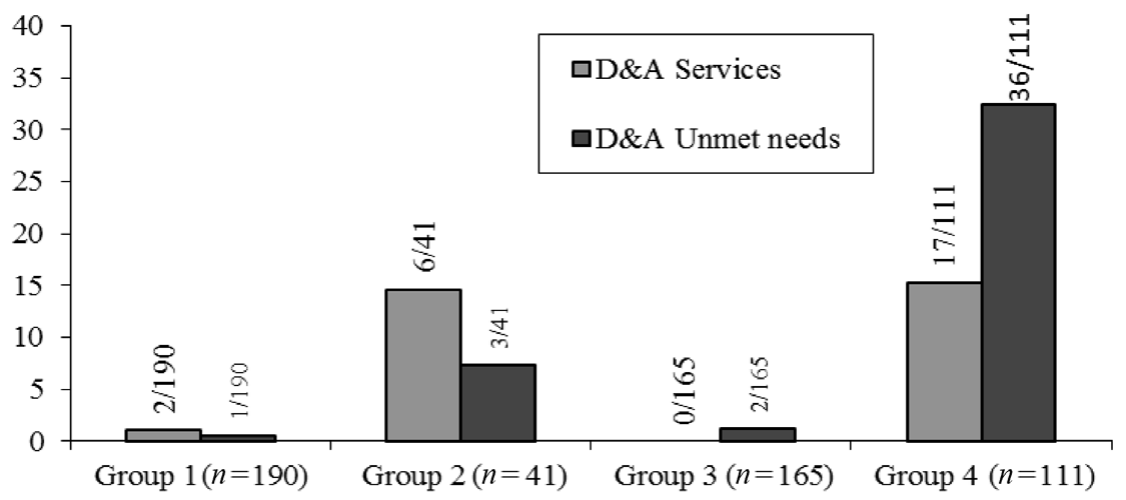

\section{FIGURE 2}

Proportion of clients with challenging behaviour and mental health or drug and alcohol co-morbidity who receive specialist services and who have unmet needs for these services ( $N=507)$. Group 1, no challenging behaviour, no co-morbidity; Group 2, no challenging behaviour, with co-morbidity; Group 3, challenging behaviour, no co-morbidity; Group 4, challenging behaviour, with co-morbidity. Groups are not independent 9 clients identified as having mental health unmet needs have also accessed specialist mental health services, while 4 clients identified as having drug and alcohol unmet needs have also accessed specialist drug and alcohol services). $M H$, mental health; D\&A, drug and alcohol.

conditions (presence versus absence of comorbidity $\times$ presence versus absence of challenging behaviours) for both mental health state and drug and alcohol use. Frequencies were then generated for services accessed and unmet needs across the four conditions (see Figure 2). Visual inspection of the figure shows that, as expected, virtually no clients in Group 1 (no challenging behaviour, no co-morbidity) were using or had unmet needs for mental health or drug and alcohol services. Group 2 (no challenging behaviour with co-morbidity) also showed a similar pattern of service use for clients with either mental health or drug and alcohol problems but no challenging behaviours. For each co-morbidity, a greater proportion of clients were accessing services compared to the number who had unmet needs. The pattern of service use diverged for Group 3 (challenging behaviour, no co-morbidity). In this condition, an equal number of clients had accessed or had unmet needs for mental health services, suggesting that such services were still being used in some cases to 
help manage challenging behaviour among clients with no mental health problems, whereas no such service use or unmet need was reported for drug and alcohol services in the absence of drug and alcohol problems. Finally, for Group 4 (challenging behaviour and co-morbidity), equal numbers of clients with mental health co-morbidities either accessed services or had unmet service needs. In contrast, there was double the level of unmet needs among clients with a drug and alcohol comorbidity compared to the number of clients able to access drug and alcohol services.

\section{Discussion}

The study found that the presence of challenging behaviour was an independent predictor of higher levels of service utilisation among communitydwelling adults with severe TBI, in conjunction with the presence of pre- and post-injury comorbidities and geographic location (specifically, living in a rural or remote area). Challenging behaviours were associated with higher use of BIRP and non-BIRP services and greater levels of unmet needs. In contrast, the degree of functional impairment, as measured by the DRS, did not correlate with the total service utilisation aggregate, despite $41.2 \%$ of clients classified as having a moderate, severe or extremely severe disability.

The level of variance accounted for by the current model was modest in comparison to the previous New South Wales service utilisation study by Hodgkinson et al. (2000). Regression analysis in their paper found that injury severity (as measured by post-traumatic amnesia or loss of consciousness) combined with functional outcome accounted for approximately $40 \%$ of the variance in the number of services used. However, it was a single-centre study, and part of the lower level of variance accounted for in the current study may be due to a greater variation in patterns of service use across the 11 participating centres. Furthermore, the current study employed a different approach to categorising services, and this may also account for the difference in the level of variance explained. The model employed in the current study could be further evaluated by testing the extent to which it accounts for the variance in the intensity of service use and not just the numbers of different types of service that are utilised.

It is logical that increases in service utilisation result in corresponding increases in costs. Studies that have examined the use of services and their respective costs have shown this to be the case (Ponsford et al., 2013; Prang, Ruseckaite, \& Collie, 2012; Turner-Stokes \& Nyein, 1999). Two recent reviews have been conducted into the service-related impact of challenging behaviours among brain-injured participants of statutory schemes providing lifetime support to people injured in road accidents within Australia. The Victorian Transport Accident Commission found that $21 \%$ of its Lifetime Care budget for clients with severe TBI related to challenging behaviours (National Trauma Research Institute, 2012). Price Waterhouse Coopers estimated that clients of the NSW Life Time Care and Support Scheme with high-level cognitive and behavioural issues following severe TBI cost $50 \%$ more than persons with a comparable level of disability due to TBI but no behavioural difficulties (Price Waterhouse Coopers, 2012). In Canada, Colantonio et al. (2010) reported significant care costs associated with challenging behaviours displayed by people with TBI resident in long-term aged care homes.

To the best of our knowledge, this is the first study to find an association between preinjury or post-injury co-morbidities and longerterm community-based service utilisation among clients with severe TBI. This extends a previous finding by Ponsford et al. (2013) that preinjury psychiatric hospitalisation was associated with elevated medical costs but not longer-term community service costs. Despite the presence of challenging behaviours and co-morbidities, many clients were still able to receive concurrent rehabilitation interventions. However, clients with challenging behaviours received more services from social work and clinical psychology. The social work interventions were most likely to target family/friends supporting the client (Simpson, Simons, \& McFadyen, 2002), whereas clinical psychology was most likely involved with the provision of behavioural interventions (Wood \& McMillan, 2001) including emotional and prosocial behavioural supports (Ylvisaker \& Feeney, 1998). The substantial levels of unmet needs were similar to the reports in earlier studies (Corrigan et al., 2004; Pickelsimer et al., 2007) but the current study extends findings, documenting unmet need over a time frame extending to greater than 5 years postinjury.

A number of issues were identified in relation to mental health and drug and alcohol services. The study found initial evidence for a differential pattern of access based on the type of mental health presentation. Clients displaying symptoms of acute psychosis or at high risk of self-harm appeared to have better access than clients with depressive symptoms or other mental health problems. One caution though is the small numbers of clients associated with this result and further larger-scale studies will be required to confirm these initial findings. 
Much lower rates of clients with moderate to severe levels of depressive symptoms after TBI accessed services, suggesting that significant numbers of people with TBI were experiencing untreated depression. Substantial rates of untreated or undertreated depression have been reported in other neurological groups, including multiple sclerosis (Feinstein, 2002) and spinal cord injury (Fann et al., 2011). Many problems can arise from untreated depression (Agency for Healthcare Research and Quality, 2011), not least of all the possible risk of suicide (Simpson \& Tate, 2007).

There is a close relationship between challenging behaviours and co-morbid mental health disorders and/or drug and alcohol abuse (e.g., Baguley et al., 2006; Rao et al., 2009; Sabaz et al., 2014). The current study provided the opportunity to tease out some of the differential effects of challenging behaviours with or without co-morbidities in service access. One finding was that people with challenging behaviours but no co-morbidities were still being linked with mental health services. Historically, such clients had limited alternatives for management apart from secure mental health units (Manchester et al., 1997; Wood, 1987). However, alternative specialist neurobehavioural services have been able to demonstrate their efficacy in treating severe challenging behaviours (Alderman, Knight, \& Brooks, 2013; Manchester et al., 1997). Therefore, it will be important to further investigate whether the sole reason for the clients with challenging behaviours but no mental health comorbidities accessing mental health services was the lack of appropriate alternative service options.

Second, the level of unmet needs for drug and alcohol services was double the number of clients able to access such services. It is a common enough experience within the drug and alcohol field that individuals with significant drug and alcohol problems lack the motivation and/or the awareness of the impact of their respective substance abuse/ dependence disorder (Burke, Arkowitz, \& Menchola, 2003). However, people with TBI may have additional challenges with insight due to the frontally mediated impairments characteristic of this type of injury (Fleming \& Ownsworth, 2006). This additional level of impairment may mean that some people with TBI are unable to meet the higher demand characteristics that drug and alcohol services require of clients in taking individual responsibility and motivation to access treatment. The finding once again reinforces the call for services with specialist expertise to manage people with both severe TBI and co-morbid substance use disorders (Bogner \& Corrigan, 2013).

There are a number of limitations to the study findings that need to be taken into account. First, the data collected were on the categories of services accessed, but not the intensity of service provision (i.e., the actual amount of services received), and the latter data may have a different pattern of relationship to challenging behaviour (e.g., the number of service categories may underestimate the degree of service intensity). In addition, data on unmet needs for BIRP services were not collected. Although the BIRP units provide services on a needs-basis it could not be assumed that all required services were provided, and therefore the results may underestimate the full extent of service needs. Next, the study was cross-sectional and so it is not known how patterns of service use might change over time. Moreover, data on the services were not collected using a validated instrument which may have strengthened the reliability. In addition, the services identified in the study are available within New South Wales. Differences in service systems or access arrangements for people with severe TBI in other state, provincial or national settings may limit the degree to which the current findings could be generalised.

Given these caveats, a number of clinical and service implications can be drawn from the study. It is important for staff in the field of TBI to have competencies in being able to manage challenging behaviours (Jackson \& Manchester, 2001). Furthermore, the percentage of clients with premorbid co-morbidities needing post-injury mental health or drug and alcohol services highlights the need for clinical pathways that address this need. The findings also reinforce calls for specialist services that are able to manage extremely challenging cases (Manchester et al., 1997; Bogner \& Corrigan, 2013), albeit for a relatively small proportion of all community-dwelling adults with severe TBI. Finally, future research could examine the costs associated with the various types and intensity of services provided to people with TBI in non-inpatient settings, as there are limited data available about the costs associated with longer-term community support. Also, further investigation into the amount of informal care provided by caregivers will assist in understanding the full level of support required by people with severe TBI in community settings.

\section{Acknowledgments}

The New South Wales Agency for Clinical Innovation (ACI) funded the project. Dr Mark Sabaz was employed by ACI while undertaking the project. Thanks to Dr Jeff Rogers, Inika Gillis, the project steering committee and the participating BIRP clinicians. 


\section{Conflicts of interest}

The authors declare no conflicts of interest.

\section{References}

Agency for Healthcare Research and Quality. (2011). Traumatic brain injury and depression. Nashville, TN: Vanderbilt Evidence-based Practice Center.

Alderman, N. (2007). Prevalence, characteristics and causes of aggressive behaviour observed within a neurobehavioural rehabilitation service: Predictors and implications for management. Brain Injury, 21(9), 891-911.

Alderman, N., Knight, C., \& Brooks, J. (2013). Rehabilitation approaches to the management of aggressive behaviour disorders after acquired brain injury. Brain Impairment, 14(1), 5-20.

Baguley, I.J., Cooper, J., \& Felmingham, K. (2006). Aggressive behavior following traumatic brain injury: How common is common? Journal of Head Trauma Rehabilitation, 21(1), 45-56.

Belanger, H.G., King-Kallimanis, B., Nelson, A.L., Schonfeld, L., Scott, S.G., \& Vanderploeg, R.D. (2008). Characterizing wandering behaviors in persons with traumatic brain injury residing in veterans health administration nursing homes. Archives of Physical Medicine and Rehabilitation, 89(2), 244250.

Bogner, J., \& Corrigan, J.D. (2013). Interventions for substance misuse following TBI: A systematic review. Brain Impairment, 14(1), 77-91.

Burke, B.L., Arkowitz, H., \& Menchola, M. (2003). The efficacy of motivational interviewing: A metaanalysis of controlled clinical trials. Journal of Consulting and Clinical Psychology, 71(5), 843.

Coetzer, R., \& Du Toit, P.L. (2001). HoNOS-ABI; A clinically useful outcome measure? Psychiatric Bulletin, 25(11), 421-422.

Cohen, J. (1992). A power primer. Psychological Bulletin, 112(1), 155-159.

Colantonio, A., Howse, D., \& Patel, J. (2010). Young adults with traumatic brain injury in long-term care homes: A population-based study. Brain Impairment, 11(1), 31-36.

Corrigan, J.D., Whiteneck, G., \& Mellick, D. (2004). Perceived needs following traumatic brain injury. Journal of Head Trauma Rehabilitation, 19(3), 205216.

Eames, P., \& Wood, R. (1985). Rehabilitation after severe brain injury: A follow-up study of a behaviour modification approach. Journal of Neurology, Neurosurgery and Psychiatry, 48(7), 613-619.

Fann, J.R., Bombardier, C.H., Richards, J.S., Tate, D.G., Wilson, C.S., \& Temkin, N. (2011). Depression after spinal cord injury: Comorbidities, mental health service use, and adequacy of treatment. Archives of Physical Medicine and Rehabilitation, 92(3), 352360.
Feeney, T.J., Ylvisaker, M., Rosen, B.H., \& Greene, P. (2001). Community supports for individuals with challenging behavior after brain injury: An analysis of the New York State Behavioral Resource Project. Journal of Head Trauma Rehabilitation, 16(1), 6175 .

Feinstein, A. (2002). An examination of suicidal intent in patients with multiple sclerosis. Neurology, 59(5), 674-678.

Fleming, J., \& Ownsworth, T. (2006). A review of awareness interventions in brain injury rehabilitation. Neuropsychological Rehabilitation, 16(4), 474500.

Fleminger, S., Leigh, E., Eames, P., Langrell, L., Nagraj, R., \& Logsdail, S. (2005). HoNOS-ABI: A reliable outcome measure of neuropsychiatric sequelae to brain injury? Psychiatric Bulletin, 29(2), 53-55.

Grafman, J., Schwab, K., Warden, D., Pridgen, A., Brown, H., \& Salazar, A. (1996). Frontal lobe injuries, violence, and aggression. Neurology, 46(5), 1231-1238.

Heinemann, A., Sokal, K., Garvin, L., \& Bode, R.K. (2002). Measuring unmet needs and services among persons with traumatic brain injury. Archives of Physical Medicine and Rehabilitation, 83(8), 10521059.

High, W.M., Gordon, W.A., Lehtnkuhl, L.D., Newton, C.N., Vandergoot, D., Thoi, L., \& Courtney, L. (1995). Productivity and service utilisation following traumatic brain injury: Results of a survey by the RSA regional TBI centres. Journal of Head Trauma Rehabilitation, 10(4), 64-80.

Hodgkinson, A., Veerabangsa, A., Drane, D., \& McCluskey, A. (2000). Service utilization following traumatic brain injury. Journal of Head Trauma Rehabilitation, 15(6), 1208-1226.

Jackson, H., \& Manchester, D. (2001). Towards the development of brain injury specialists. NeuroRehabilitation, 16(1), 27-40.

James, A.I., \& Young, A.W. (2013). Clinical correlates of verbal aggression, physical aggression and inappropriate sexual behaviour after brain injury. Brain Injury, 27(10), 1162-1172.

Kelly, G., Brown, S., Todd, J., \& Kremer, P. (2008). Challenging behaviour profiles of people with acquired brain injury living in community settings. Brain Injury, 22(6), 457-470.

Kelly, G., \& Parry, A. (2008). Managing challenging behaviour of people with acquired brain injury in community settings: The first 7 years of a specialist clinical service. Brain Impairment, 9(3), 293-304.

Kelly, G., Todd, J., Simpson, G., Kremer, P., \& Martin, C. (2006). The Overt Behaviour Scale (OBS): A tool for measuring challenging behaviours following $\mathrm{ABI}$ in community settings. Brain Injury, 20(3), 307-319.

Koponen, S., Taiminen, T., Portin, R., Himanen, L., Isoniemi, H., Heinonen, H., . . . Tenovuo, O. (2002). Axis I and II psychiatric disorders after traumatic brain injury: A 30-year follow-up study. American Journal of Psychiatry, 159(8), 1315-1321. 
Manchester, D., Hodgkinson, A., \& Casey, T. (1997). Prolonged, severe behavioural disturbance following traumatic brain injury: What can be done? Brain Injury, 11(8), 605-618.

Marwitz, J.H., Cifu, D.X., Englander, J., \& High, W.M. (2001). A multi-center analysis of rehospitalizations five years after brain injury. Journal of Head Trauma Rehabilitation, 16(4), 307-317.

National Trauma Research Institute. (2012). Developing a research program to address behaviours of concern after traumatic brain injury - briefing document. Melbourne, Australia: NTRI.

Pickelsimer, E.E., Selassie, A.W., Sample, P.L., Heinemann, A.W., Gu, J.K., \& Veldheer, L.C. (2007). Unmet service needs of persons with traumatic brain injury. Journal of Head Trauma Rehabilitation, 22(1), 1-13.

Ponsford, J.L., Downing, M.G., Olver, J., Ponsford, M., Acher, R., Carty, M., \& Spitz, G. (2013). Longitudinal follow-up of patients with traumatic brain injury: Outcome at 2, 5, and 10-years post-injury. Journal of Neurotrauma, 31(1), 64-77.

Prang, K.-H., Ruseckaite, R., \& Collie, A. (2012). Healthcare and disability service utilisation following transport-related traumatic brain injury. Brain Injury, 26(4-5), 441-442.

Price Waterhouse Coopers. (2012). A joint agency ABI challenging behaviour intervention and support service: feasibility study. NSW, Australia: Department of Family and Community Services.

Rao, V., Rosenberg, P., Bertrand, M., Salehinia, S., Spiro, J., Vaishnavi, S., . . . Miles, Q.S. (2009). Aggression after traumatic brain injury: Prevalence \& correlates. Journal of Neuropsychiatry and Clinical Neurosciences, 21(4), 420-429.

Rappaport, M., Hall, K.M., Hopkins, K., Belleza, T., \& Cope, D.N. (1982). Disability rating scale for severe head trauma: Coma to community. Archives of Physical Medicine and Rehabilitation, 63(3), 118-123.

Sabaz, M. (2010). NSW Brain Injury Rehabilitation Program Challenging Behaviour Project: Adults. Using the analysis of prevalence, course, co-morbidity and burden to inform the model of care. Sydney, Australia: NSW Agency for Clinical Innovation.

Sabaz, M., Simpson, G.K., Walker, A.J., Rogers, J.M., Gillis, I., \& Strettles, B. (2014). Prevalence, comorbidities, and correlates of challenging behavior among community-dwelling adults with severe traumatic brain injury: A multicenter study. Journal of Head Trauma Rehabilitation, 29(2), E19-E30.
Simpson, G., Simons, M., \& McFadyen, M. (2002). The challenges of a hidden disability: Social work practice in the field of traumatic brain injury. Australian Social Work, 55(1), 24-37.

Simpson, G., \& Tate, R. (2007). Suicidality in people surviving a traumatic brain injury: Prevalence, risk factors and implications for clinical management. Brain Injury, 21(13-14), 1335-1351.

Simpson, G.K., Sabaz, M., \& Daher, M. (2013). Prevalence, clinical features, and correlates of inappropriate sexual behavior after traumatic brain injury: A multicenter study. Journal of Head Trauma Rehabilitation, 28(3), 202-210.

Sloan, S., Winkler, D., \& Callaway, L. (2004). Community integration following severe traumatic brain injury: Outcomes and best practice. Brain Impairment, 5(1), 12-29.

Teasdale, G.M. (1995). Head injury. Journal of Neurology, Neurosurgery and Psychiatry, 58(5), 526539.

Todd, J., Loewy, J., Kelly, G., \& Simpson, G. (2004). Managing challenging behaviours: Getting interventions to work in nonspecialised community settings. Brain Impairment, 5(1), 42-52.

Turner-Stokes, L., \& Nyein, K. (1999). The Northwick Park Care Needs Assessment (NPCNA): A directly costable outcome measure in rehabilitation. Clinical Rehabilitation, 13(3), 253-267.

Willemse-van Son, A.H., Ribbers, G.M., Stam, H.J., \& van den Bos, G.A. (2009). Is there equity in longterm healthcare utilization after traumatic brain injury? Journal of Rehabilitation Medicine, 41(1), 5965 .

Winkler, D., Sloan, S., \& Callaway, L. (2010). People under 50 with acquired brain injury living in residential aged care. Brain Impairment, 11(3), 299-312.

Wood, R. (1987). Brain injury rehabilitation: A neurobehavioural approach. London: Croom Helm.

Wood, R., \& Liossi, C. (2006). Neuropsychological and neurobehavioral correlates of aggression following traumatic brain injury. Journal of Neuropsychiatry and Clinical Neurosciences, 18(3), 333-341.

Wood, R.L., \& McMillan, T.M. (Eds.). (2001). Neurobehavioural disability and social handicap following traumatic brain injury. East Sussex, UK: Psychology Press.

Ylvisaker, M., \& Feeney, T.J. (1998). Collaborative brain injury intervention: Positive everyday routines. San Diego, USA: Singular Publishing Group. 